\title{
Sociedade e gestão do risco: o aquífero Guarani em Ribeirão Preto-SP, Brasil ${ }^{1}$
}

\author{
Pilar Carolina Villar ${ }^{2}$ y Wagner Costa Ribeiro ${ }^{1}$
}

\begin{abstract}
RESUMO
A sociedade contemporânea cria riscos de todas ordens, alterando o significado dessa palavra. Ela pode estar associada a ameaças naturais, mas cada vez mais esta relacionada a açıes humanas, em especial devido ao uso de tecnologias. O uso do solo, tanto para fins agrícolas quanto urbano, gera possibilidades de contaminação de áreas sensíveis, como é o caso da área de recarga do aquífero Guarani, em Ribeirão Preto, no Estado de São Paulo, no Brasil, um dos mais importantes municípios do estado que, além de elevado desenvolvimento econômico, destaca-se por situar-se junto a área de recarga do principal reservatório de água subterrânea do Cone Sul. Este trabalho visa discutir a gestão do uso das águas subterrâneas em Ribeirão Preto e refletir sobre os riscos que a contaminação e a superexploração acarretam para a principal fonte hídrica do município.
\end{abstract}

Palavras chave: Sociedade de risco, aqüífero Guarani, políticas públicas ambientais.

\begin{abstract}
Contemporary society creates risks of all kinds, changing the meaning of this term. Although it may be associated with natural hazards, it gradually assumes a stronger relation with human actions, especially due to the use of technology. The use of land for agricultural and urban activities creates the possibility of contamination in the recharge area of the Guarani aquifer in the municipality of Ribeirão Preto, state of Sao Paulo, Brazil. This city is one of the most important in the state with high economic development. Besides this, it is located in the recharge area of the main reservoir of underground water of South Cone. This paper aims to discuss the management of groundwater use in Ribeirão Preto and reflects the risk that contamination and overexploitation might cause to the main city's water supply.
\end{abstract}

Key words: Risk society, Guarani aquifer, environmental policies.

1 Artículo recibido el 11 de octubre de 2008 y aceptado el 27 de abril de 2009.
2 Departamento de Geografía, Programa de PósGraduação em Ciência tal (PROCAM), Universidade de São Paulo (USP). E-mail: pcvillar@usp.br; wribeiro@usp.br 
A gestão dos riscos socioambientais envolve diversos setores. Quando eles estão associados às águas subterrâneas, a contaminação e a superexploração das reservas são as mais freqüentes. O município de Ribeirão Preto localizado no Estado de São Paulo no Brasil é um exemplo dessa exploração.

Ribeirão Preto explora o Sistema Aqüífero Guarani desde o início do século XX. Esse aqüífero, conforme demostra a Figura $N^{0} 1$, é transfronteiriço e ocupa uma área estimada em $1.195 .500 \mathrm{~km}_{-}$, que se estende pela
Argentina, Paraguai, Uruguai e Brasil. Nesse país, é compartilhado por oito estados Mato Grosso do Sul, Rio Grande do Sul, São Paulo, Paraná, Goiás, Minas Gerais, Santa Catarina e Mato Grosso (Borguetti et al., 2004).

Esse município ocupa uma área de 650 $\mathrm{km}^{2}$ e se localiza na região nordeste do Estado de São Paulo a 313 km da capital São Paulo (Figura $N^{\circ} 1$ ). A população é de aproximadamente de 550.000 habitantes e a economia está focada no setor de serviços. Diante de sua localização privilegiada em relação a importantes centros consumidores

Figura $\mathrm{N}^{0} 1$

Sistema Aqüífero Guarani

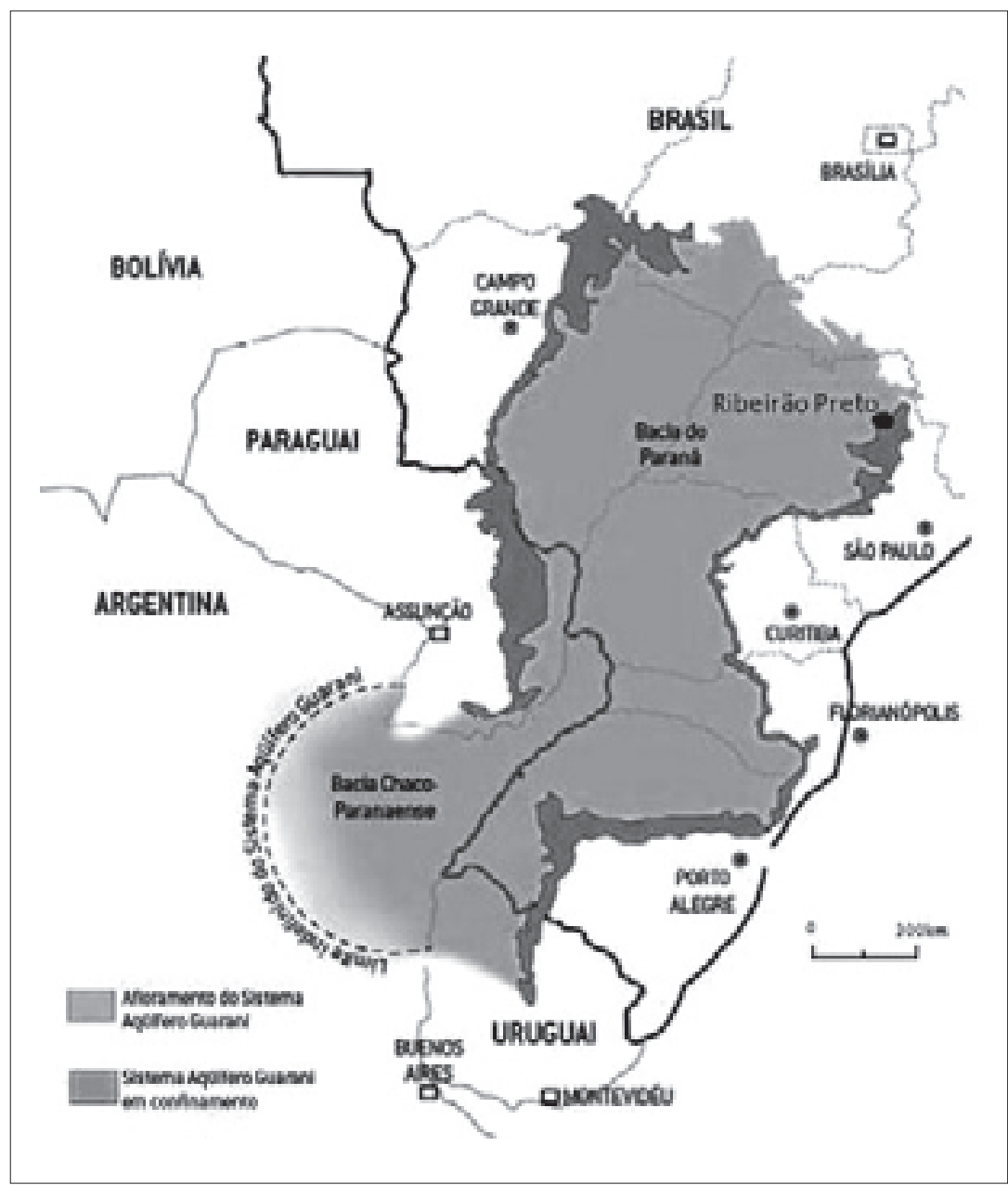

Fuente: Borguetti et al., 2004. 
e da ampla infra-estrutura de transportes e comunicação, consolidou-se como um de um pólo de atração regional para atividades comerciais e de prestação de serviços. Além disso, é um dos mais municípios de maior renda do estado, graças a vitalidade da agroindústria baseada no cultivo da canade-açúcar (IBGE, 2006).

A partir da década de 1960, o uso de água se intensificou no município. O número de poços saltou de 10 para 45 no ano de 1970, e, no início do século XXI é de aproximadamente 400 (Perticarrari, 2003). O responsável pelo abastecimento público municipal é o Departamento de Água e Esgoto de Ribeirão Preto-DAERP que possui 193 poços, dos quais 97 estão em funcionamento. As águas subterrâneas são a única fonte utilizada para abastecer a área urbana. Embora sua importância seja inegável, foram poucas as medidas de gestão adotadas para promover um uso racional do recurso.

Esse aqüífero é o responsável por fornecer água de qualidade aos habitantes e sustentar os processos produtivos que se desenvolvem no município. A permanente expansão da ocupação humana, seguida de instalaçıes materiais gera municípios insaciáveis por água. Para saciar a sede dos seres humanos, animais, irrigação, limpeza pública, lazer, indústria promovese um consumo cada vez mais insustentável.

O objeto desse artigo é discutir a gestão do uso das águas subterrâneas em Ribeirão Preto e refletir sobre os riscos que a contaminação e a superexploração acarretam para a principal fonte hídrica do município. Por isso o referencial teórico que norteia este estudo é o da sociedade de risco.

A construção desse referencial foi realizada a partir de uma ampla pesquisa bibliográfica que permitiu enriquecer e ampliar as variáveis incorporadas aos estudos de campo. Optou-se por sua análise qualitativa e por uma pesquisa bibliográfica e documental. Levantou-se o volume de informação já produzido sobre o Aqüífero Guarani nos âmbitos técnicos e acadêmicos com o principal objetivo de compreende-los à luz da teoria social do risco.

A escolha por essa teoria se deu pela extensa gama de agentes poluidores e riscos ambientais aos quais as águas subterrâneas estão submetidas. O risco pode ser entendido como um resultado do estágio de produção industrial e agrícola e pelos efeitos secundários sistemáticos dos processos de modernização. Trata-se de um resultado, muitas vezes indesejado, das açıes e omissıes humanas realizadas no desenvolvimento das forças produtivas e do período técnico-cientifico-informacional (Zanirato et al., 2008).

Também adotou-se o estudo de caso, na medida em que o foco da pesquisa está em entender de forma profunda e detalhada o assunto pesquisado. Outra razão que justifica essa escolha é o caráter exploratório do trabalho. Diante do número reduzido de pesquisas existentes nessa temática, a observação de um caso em particular é a melhor forma de buscar indícios que possam corroborar ou refutar hipóteses iniciais.

A escolha do município de Ribeirão Preto se justificou diante da completa dependência do abastecimento público das águas desse Aqüífero, da diversidade de atividades econômicas desenvolvidas, da existência de áreas de recarga vulneráveis, além da realização de vários projetos, inclusive internacionais na área, que forneceram os dados técnicos necessários para a elaboração deste trabalho. Os desafios enfrentados na gestão das águas subterrâneas, motivaram sua escolha como uma das áreas piloto do Projeto Aqüífero Guarani $^{3}$, o que garantiria dados técnicos atualizados e uma receptibilidade social

3 Esse projeto conta com o apoio do Banco Mundial, da Organização dos Estados Americanos (OEA) e do Fundo para o Meio Ambiente Mundial (GEF) tendo como principais objetivos: apoiar a Argentina, Brasil, Paraguai e Uruguai na elaboração e implementação coordenada de uma proposta de modelo institucional, legal e técnico comum para a preservação e o gerenciamento do Sistema Aqüífero Guarani-SAG para as geraçıes atuais e futuras. 
maior para esse tema, criando uma maior demanda municipal por políticas públicas ${ }^{4}$ aplicáveis às águas subterrâneas. Diante de todas essas peculiaridades, optou-se por focar a análise nas políticas ambientais implementadas no município referentes à proteção das áreas de recarga do aquífero Guarani.

Para tratar desses temas, este trabalho está dividido em quatro partes: a sociedade de risco, na qual se sistematiza uma reflexão sobre a contemporaneidade e a criação social dos riscos, riscos à área de recarga em Ribeirão Preto, onde são expostos os principais riscos à contaminação do aqüífero Guarani, e a gestão do risco, no qual se encontram as políticas implementadas em Ribeirão Preto e, por fim, as consideraçıes finais.

\section{A sociedade de risco}

No passado a natureza era enxergada como fonte de riscos, enquanto, o progresso científico seria o meio de se atingir a segurança total, com o desaparecimento das incertezas e perigos (Veyret, 2007). A valorização e progressivo crescimento das cidades se ligava a essa idéia, a incerteza das relaçıes no estado da natureza era substituída pela criação da cidade que representava a estabilidade e a continuidade. Estas representavam a emancipação do meio local e a dominação humana mais ampla sobre a terra (Vidal de la Blache, 1898).

Contudo, todo esse progresso científico baseado na dominação e subjugação da natureza trouxe novos riscos, cujos efeitos começaram a ser sentidos especialmente nas ultimas décadas (Calvo, 1997, 2001; November, 2002). Os chamados "riscos fabricados" (Giddens, 2002) ou "riscos

\footnotetext{
4 Políticas públicas são definidas nesse texto como a capacidade de antecipação do Estado em prover as bases para a reprodução da vida de sua população. É evidente que elas geram conflitos pois o bloco no poder nem sempre assume como demandas do Estado as que afligem a maior parte da população e, mesmo quando o fazem, não conseguem implementar açıes sem afrontar interesses.
}

tecnológicos" (Beck, 2006; Carpenter, 1995) provenientes do desenvolvimento tecnológico e científico, e que podem ser químicos, físicos, biológicos ou socioculturais. Tais riscos, muitas vezes, se caracterizam por não mais serem perceptíveis pelos sentidos, provocando danos sistemáticos e irreversíveis (Beck, 2006).

A tecnologia alterou os sentidos do risco. Se antes os perigos advinham da escassez de tecnologia, agora, muitos deles são produto da modernização tecnocientífica, e nem todos podem ser percebidos.

Diante desse caráter novo e único dos riscos, Beck (2006) afirma que a humanidade vive atualmente em uma Sociedade de Risco. Trata-se da sociedade pós-industrial, caracterizada pela produção social da riqueza acompanhada sistematicamente pela produção social de riscos. Além disso, ela gera também negócios do risco, como o setor de seguros. Essa forma de organização social é fruto da modernidade, da ideologia do progresso e da confiança na infalibilidade da ciência (Lemkow, 2002).

O progresso técnico tão enaltecido não é isento de efeitos negativos, os quais, muitas vezes, só são percebidos a médio e longo prazos. A forma tradicional de risco foi rompida e substituída por um risco que não se restringe ao local que o produziu, nem tampouco às conseqüências esperadas (Beck, 2006).

Segundo Beck (2006), o risco é uma maneira sistemática de lidar com os perigos e as incertezas induzidas e produzidas pela própria modernização. Na medida em que se opıem aos antigos perigos, os riscos tornam-se conseqüências relacionadas com a ameaçadora força da modernização e a respectiva globalização da dúvida. São "politicamente reflexivos" (Beck, 2006). Para ele, a modernidade poderia ser subdivida em dois momentos: a primeira modernidade, na qual ciência e tecnologia tinham uma grande legitimação social, sendo consideradas o caminho para o desenvolvimento e prosperidade; e a segunda modernidade, no qual o 
desenvolvimento científico passa a ser percebido como principal causa da exposição humana aos riscos (Beck, 2006).

A Sociedade de Risco é o resultado de um processo de modernização alheio às suas conseqüências. Quanto mais a Sociedade Industrial se afirma, mais depressa é encoberta pela Sociedade de Risco. Não se trata de um processo intencional ou escolhido, mas de uma conseqüência inerente ao processo tecnológico (Demajorovic, 2003; Setzer, 2007).

Por estar emersa em riscos, a sociedade gerou uma capacidade de reflexão sobre si mesma. A reflexividade possibilita que a sociedade reconheça as "incertezas manufaturadas", isto é, as incertezas criadas pelo próprio desenvolvimento tecnocientífico (Giddens, 1991). Trata-se de uma condição que busca pensar sobre o estilo de vida, seus riscos e efeitos para a sociedade (Zanirato et al., 2008).

\section{Riscos à área de recarga em Ribeirão Preto}

No município de Ribeirão Preto tem-se o retrato da sociedade de risco. Ao mesmo tempo em que a população é vítima de uma ameaça resultante de sua modernização e desenvolvimento, parte dela é culpada por provocar os riscos que afligem a todos. Justamente por esse duplo caráter ativo e passivo do risco, a sociedade busca o controle das ameaças criadas por ela própria por meio da gestão dos riscos.

A busca por água, aliada à falta de uma política de gestão, gerou um rebaixamento dos níveis dinâmicos do aqüífero na porção urbana de aproximadamente 60 metros. A exploração hídrica atualmente é de $95.700 .000 \mathrm{~m}^{3}$, treze vezes superior à recarga da chuva. Ainda que o meio técnico-acadêmico tenha alertado para o risco de superexploração, não se buscaram fontes alternativas de abastecimento. Mesmo que o Rio Pardo e os seus tributários cortem o território municipal, não houve a preocupação em revitalizar tais rios. Tampouco se incentivou o uso eficiente da água, a diminuição das perdas no sistema de abastecimento e o uso racional de água por parte da população que consome uma media de 348 l/hab/dia, quando a media nacional é de 200 l/hab/dia (Perticarrari, 2003).

Os recursos hídricos subterrâneos estão comprometidos nos aspectos quantitativo e qualitativo graças ao dinamismo econômico do município, baseado numa gama de atividades impactantes muito variada. A situação se agrava diante da existência de áreas de recarga, naturalmente mais vulneráveis à poluição. A Bacia do rio Pardo tem uma área de afloramento de $1.327 \mathrm{~km}^{2}$, da qual $10 \%$ se localiza no município de Ribeirão Preto $\left(137 \mathrm{~km}^{2}\right.$, ou $21 \%$ da área total do município).

A Figura $\mathrm{N}^{0} 2$ demonstra a presença da mancha urbana sobre a área de recarga, que se localiza no zona de expansão urbana. O resultado é a impermeabilização da área de recarga e a geração de novos riscos. Em tais áreas ocorrem, concomitantemente, zonas urbanas e rurais, bairros são completamente rodeados pela cultura canavieira, principal atividade agrícola da região. Essa diversidade de usos urbanos e rurais gerou diversas fontes de contaminação na área de recarga: os cemitérios da cidade, bairros sem rede de esgoto, ocupaçıes irregulares (favelas), agroquímicos usados na agroindústria da cana-de-açúcar, resíduos da produção de cana-de-açúcar (vinhoto) e o antigo depósito de lixo do município.

A importância econômica de uma atividade geradora do risco ou os benefícios advindos dela também são elementos fundamentais para apurar o grau de tolerância social ao risco (Varella, 2005). Portanto, em prol do argumento da manutenção da economia e da geração de emprego, os setores produtivos têm plena liberdade para produzir riscos, ainda que boa parte da renda produzida restrinja-se a um pequeno número de beneficiários e a qualidade do emprego fornecido seja questionada.

Como exemplo dessa relação com os riscos pode-se citar o exemplo do cultivo da cana-de-açúcar, o uso de herbicidas 
persistentes e a ameaça a qualidade da água do aqüífero. Estudos realizados no município com os herbicidas Atrazina, Diuron e Tebutiuron demonstraram que 5,6\% da área de estudo apresenta exposição ao risco de contaminação das águas subterrâneas pela Atrazina, 3,9\% pelo Diuron e $13,1 \%$ pelo Tebutiuron (Pessoa et al., 2003).

No caso do Tebutiuron, uma pesquisa que analisou o período de 1995 a 1999, constatou a presença desse produto em todas as amostras analisadas, atingindo nos meses de janeiro/1995 e janeiro de 1999 as concentraçıes de $0,09 \mu \mathrm{g} / \mathrm{l}$, muito próximas aos limites estabelecidos pela Organização Mundial da Saúde (OMS) de 0,1 1 g/l por pesticida (Gomes et al., 2001).
Independente desses resultados o poder público local não tomou qualquer providencia junto aos agricultores. A discussão ficou restrita aos técnicos, o que permite questionar até mesmo os limites de contaminação estabelecidos pelos especialistas.

Alguns destes podem afirmar que não há motivos para alocar recursos em um programa de conscientização dos agricultores, ou, ainda, que não há motivos para perturbar a produção de cana-deaçúcar que gera álcool, um combustível renovável, uma alternativa "limpa" ao petróleo por um simples estudo que sequer chegou aos valores limites permitidos. Deve-se considerar que tais valores são arbitrados com base em pesquisas científicas

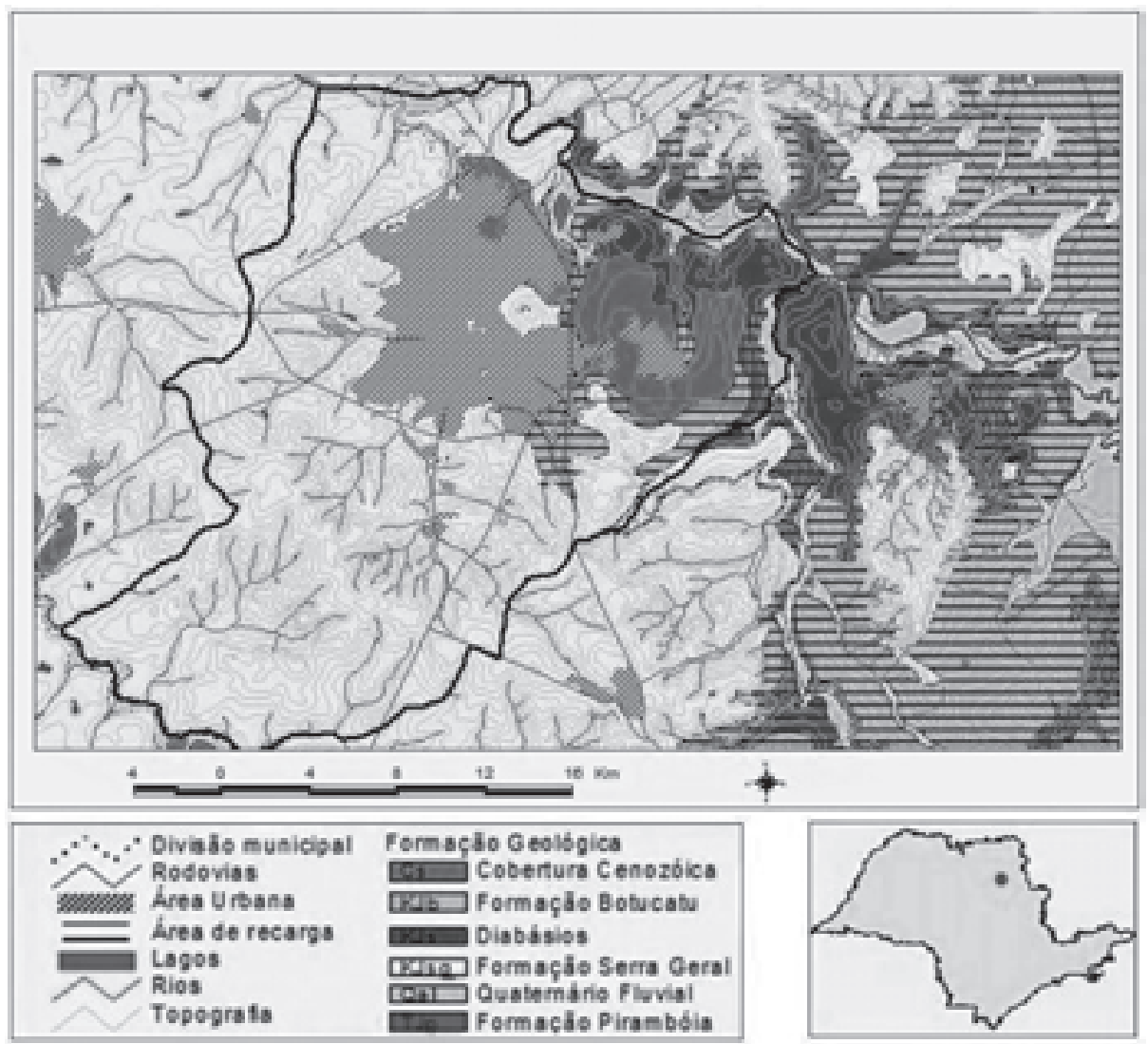

Fuente: Villar, 2008. 
que consideram o princípio nocivo isoladamente, esquecendo que a humanidade está submetida a outros princípios nocivos e que sua soma pode gerar novos limites de tolerância. Além disso, não são raros os casos de falhas na ciência ao arbitrar efeitos negativos de substâncias, como pode ser visto no exemplo do amianto (Latour, 2004). Ainda deve se considerar que tais substâncias podem ter efeitos diversos diante de pessoas distintas devido a critérios de idade, sexo, hábitos alimentares, tipo de trabalho, informação, etc (Beck, 2006).

No cenário posto, há uma forte tendência ao aumento do uso de agroquímicos, o que coloca em risco a qualidade das águas subterrâneas, especialmente porque faltam pontos de monitoramento para verificar os efeitos da vitalidade produtiva da região. Esse tipo de contaminação passa completamente despercebido da percepção humana e, diante do lento processo de movimentação da água subterrânea, pode levar anos para ser notado.

Ainda como último exemplo da negligência por parte do poder público deve se citar o caso do Lixão Serrana, onde foi comprovada a contaminação do aqüífero. Esse lixão localiza-se no quilômetro 1,5 da Rodovia Abraão Assed (SP-330) que liga Ribeirão Preto a Serrana e está na área de recarga do aqüífero. No período de 1978 a 1989, ano em que foi desativado, foram depositadas no local cerca de 110 toneladas diárias de lixo doméstico, hospitalar, industrial e de construção civil. Para agravar a situação o lixo doméstico não era acondicionado em sacos plásticos, prática implantada anos depois.

Em 1997, a Petrobrás e a Universidade de Ribeirão Preto-UNAERP realizaram um trabalho para a avaliação dos impactos ambientais causados pelo antigo "Iixão". Foi constatado que o chorume infiltrou para os arenitos da Formação Botucatu que estava em contato direto com o fundo do lixão. Os resultados mostram que a contaminação não apresenta perigo iminente para o abastecimento da cidade em decorrência do sentido do fluxo das águas subterrâneas, pois apenas as amostras do poço localizado a $20 \mathrm{~m}$ das cavas de lixo apresentaram problemas de contaminação.

Tais resultados são contestados por vários especialistas, que afirmam que os indícios de degradação distribuem-se em um halo de $150 \mathrm{~m}$ ao redor da área do lixão. Também discutem-se os aspectos locacionais e construtivos dos poços de monitoramento (Monteiro, 2003). Independente desse debate técnico, deve-se considerar que existe uma fonte permanente e constante de poluição sobre o aqüífero.

Apesar das evidências, o poder público não adotou providências para a proteção do aqüífero. Por isso o município de Ribeirão Preto é bem ilustrativo de como os riscos foram internalizados na dinâmica social e como se decidiu, sem discussão, conviver com eles (Caubet, 2005).

Salienta-se que as situaçıes de risco expostas neste trabalho não são exaustivas, nem poderiam, pois a principal característica da sociedade de risco é o reconhecimento crescente de novos graus de complexidade e incerteza ligadas ao efeitos ambientais dos riscos tecnológicos modernos (Porto, 2005). Procurou-se apenas abordar os exemplos de riscos mais evidentes pesquisados na literatura existente sobre o tema.

\section{Gestão do risco}

Políticas públicas devem ter como metas a proteção da coletividade e se antecipar aos riscos. Porém, isso implica em escolhas e, em muitos casos, em administrar conflitos e posiçıes antagônicas de setores economicamente ativos e influentes no meio político.

A gestão dos riscos está fundamentada em três elementos: a precaução, a prevenção e a indenização. A precaução determina que quando houver ameaças de danos sérios ou irreversíveis, a ausência de absoluta certeza cientifica não deve ser utilizada como razão para postergar medidas eficazes e economicamente viáveis para prevenir a degradação ambiental. A 
prevenção pretende agir antecipadamente para combater os riscos já conhecidos, seja porque já experimentados, seja porque existem técnicas capazes de prever a sua provável ocorrência. A indenização baseiase na idéia de que o dano ambiental é reparável e pode ser compensado em termos financeiros, faz com que o risco se torne aceitável na medida em que pode ser segurado no lugar de empenhar-se em prevenir a crise (Veyret, 2007).

No caso das políticas públicas destinadas as águas subterrâneas percebe-se um alto grau de desarticulação e liberdade entre as três esferas de poder: União, Estados e Municípios. A Politica Nacional de Recursos Hídricos (Lei Federal N 9.433/ 1997) representa um marco legal importante na gestão das águas, porém ela é demasiado genérica em relação as águas subterrâneas. Por sua vez a Constituição Federal reserva o domínio dos aqüíferos aos Estados, mesmo no caso de aqüíferos compartilhados ou transfronteiriços. Diante da falta de uma diretriz nacional, cada Estado possui liberdade para regular o tema, o que muitas vezes não ocorre. No caso do Estado de São Paulo, sua política de águas subterrâneas foi delineada a partir de finais da década de oitenta e inicio da década de noventa (Lei Estadual $\mathrm{N}^{\circ}$ 6.134/1988 e Decreto Regulador $\left.N^{\circ} 32.955 / 1991\right)$, porém não conseguiu transpor o papel e tornar-se uma realidade, além de conter uma serie de lacunas jurídicas. A partir dos anos 2000, percebe-se um ligeiro avanço na aplicação prática de alguns instrumentos, especialmente a outorga das águas subterrâneas. No tocante, a proteção qualitativa, ou seja das áreas mais vulneráveis, esta ocorre de forma indireta por meio de outros instrumentos ambientais como o estudo de impacto ambiental e o licenciamento ambiental (Villar, 2008).

As estratégias de proteção das águas subterrâneas podem ter dois enfoques: a proteção pontual, voltada para o controle da captação destinada ao abastecimento, e a proteção geral do aqüífero, que diz respeito à identificação das áreas mais sensíveis e a promoção de um controle do processo de uso e ocupação do solo em tais regiıes. Tais estratégias podem ferir interesses de setores econômicos influentes que não estão dispostos a ver sua liberdade de mercado tolhida por normas ambientais mais rígidas.

As estratégias de proteção aos riscos ambientais e a percepção de uma sociedade civil organizada da real gravidade dos riscos a qual ela está submetida ameaça a forma tradicional de crescimento econômico. Os setores produtivos clássicos podem enxergar a proteção do aqüífero, seja através de restriçıes ao uso e ocupação do solo ou no controle de captaçıes e novas perfuraçıes, como ameaça à expansão dos seus negócios. Daí a resistência às normas de gestão de riscos, pois elas implicam mudanças e em custos maiores no processo produtivo, podendo, inclusive, gerar perdas de negócios e incertezas no mercado.

O exposto acima pode ser facilmente ilustrado quando se observam as normas de uso e ocupação do solo em Ribeirão Preto. O Estatuto da Cidade (Lei Federal $N^{\circ}$ 10.257/2001) conferiu aos municípios a competência para gerir seu território. Como inexistem diretrizes específicas para a gestão das águas subterrâneas, o município adquire um papel fundamental na gestão desse recurso, especialmente no tocante a proteção das áreas de recarga, visto que o Poder Municipal é o principal ator na regulação do uso e ocupação do solo, aspecto vital para a manutenção da integridade dos aqüíferos. Diante da importância das águas subterrâneas para o município e as constataçıes técnicas sobre a necessidade de adotar medidas mitigadoras poderia-se esperar regulaçıes municipais que incluíssem essa componente ambiental. De certa forma, isso ocorre no Código Ambiental Municipal e no Plano Diretor que ilustram a necessidade da proteção das áreas de recarga por meio de ocupaçıes de baixas densidades populacionais e a proibição de determinadas atividades. Porém, posteriormente, a Lei de Uso e Ocupação do Solo flexibilizou esses critérios, ao estabelecer quais seriam as taxas de adensamento, garantindo a construção civil ampla liberdade de atuação.

Em uma área fundamental para a recarga da única fonte de água potável do 
município, que já apresenta níveis de rebaixamento preocupantes, classificou-se como baixas densidades a ocupação de até $850 \mathrm{hab} / \mathrm{ha}$. Essa densidade ultrapassa padrıes metropolitanos de municípios como Taboão da Serra e Campo Lindo, conhecidos por sua alta densidade populacional e que apresentam taxas entre 98,92 hab/ha e 138,41 hab/ha respectivamente. O número arbitrado é completamente inadequado e contraditório ao propósito do Plano Diretor e do Código Ambiental, que pretendiam garantir a manutenção da permeabilidade do solo.

Percebe-se que falta ambição para as políticas de saúde e meio ambiente que, ignorando os riscos, administram uma sociedade de produção da poluição, mesmo porque a vontade de suprimir essa poluição equivaleria a criticar a civilização técnica em suas próprias bases (Hermite, 2005). Um levantamento realizado pelo Ministério da Saúde revelou que existem no país cerca de 15.000 áreas contaminadas (solo e ou água) e que aproximadamente 1,3 bilhões de habitantes estão expostos diretamente nessas regiões (Agência Nacional de Água, 2007). O Estado de São Paulo registrou 2.272 áreas contaminadas (São Paulo, 2007).

A gestão do Aqüífero Guarani por parte da Administração Pública por meio de normas mais rígidas significaria uma atuação contra o sistema produtivo, uma vez que a restrição ao uso de matérias-primas fundamentais como água e solo, pressupıe restriçıes à produção e ao consumo, limitando assim o poder das classes dominantes. Essa dificuldade começa a ser discutida, como apontam os trabalhos de Camargo e Ribeiro (2009a), de Caubet (2009) e de Ribeiro (2008a).

Ao analisar o histórico das tentativas de gestão dos riscos referentes ao aqüífero percebe que a maior parte delas não atingiu os objetivos propostos. Os primeiros projetos elaborados remontam à década de 1980 e já sinalizavam uma exploração das águas subterrâneas insustentável. Contudo, tanto o Programa de Estudo e Controle do Aqüífero Botucatu em Ribeirão Preto (1983) quanto o Programa de Desenvolvimento de um Modelo Operacional para o Aproveitamento das Águas Subterrâneas em Ribeirão Preto (1986) não conseguiram atingir as metas pretendidas por falta de recursos humanos, técnicos e financeiros.

Cada sociedade mantém uma "relação com os riscos", isto é, uma forma peculiar de enfrentá-los, que transparece em um plano cultural. Essa relação de risco muda conforme as épocas e os lugares (Beck, 2006). Em Ribeirão Preto observaram-se alteraçıes em relação à gestão dos riscos de contaminação da área de recarga do aqüífero Guarani. Enquanto a década de 1980 ficou marcada pelos projetos frustrados, a seguinte pelo esquecimento do tema, o ano de 2000 marca o ressurgimento da questão das águas subterrâneas em proporçıes inéditas.

Após décadas restritas aos cursos de geologia e de engenharia, as águas subterrâneas ressurgem no cenário político e se tornam assunto obrigatório na imprensa graças ao Projeto Proteção Ambiental e Gerenciamento Sustentável Integrado do Sistema Aqüífero Guarani ou Projeto Aqüífero Guarani, que deu uma grande visibilidade ao assunto.

As proporçıes do projeto, que envolve os quatro países do Cone Sul, os investimentos estrangeiros, a constatação do potencial hídrico do aqüífero em um cenário de escassez mundial e a escolha da cidade de Ribeirão Preto como área piloto do Projeto provocaram a mobilização dos grupos de interesse e trouxeram o tema para a pauta de discussies, inclusive da mídia.

Ribeirão Preto também foi objeto de estudo de um convênio internacional firmado entre a Secretaria do Meio Ambiente do Estado de São Paulo e a Secretaria de Meio Ambiente, Saúde Pública e Proteção ao Consumidor do Estado da Baviera (Alemanha). Essa iniciativa gerou $\mathrm{o}$ Termo de Cooperação Técnica, cujos resultados culminaram na elaboração da proposta de um projeto conjunto entre a SMA/SP e o StMLU/Baviera denominado "Sistema Piloto de Informação para o Gerenciamento Ambiental dos Recursos Hídricos Subterrâneos na Área de 
Afloramento do Sistema Aqüífero Guarani no Estado de São Paulo".

Toda essa efervescência sobre o tema não se traduziu em sua plenitude na forma de políticas públicas de proteção. Se na questão da quantidade extraída a aprovação pelo Conselho Estadual de Recursos Hídricos da deliberação $N^{\circ} 47$, que proíbe a perfuração de novos poços na área urbana, representou um grande avanço, na questão do uso e ocupação do solo as normas editadas foram sofríveis.

Não obstante o discurso político afirmar que o risco de contaminação e superexploração são uma prioridade e sobre a importância em proteger o aqüífero para as futuras geraçıes, a realidade demonstrada pelos instrumentos de gestão é distinta. As leis ambientais existentes não conseguem controlar os riscos produzidos por uma sociedade formada por contingências e, paralelamente, as que surgem espelham-se e perpetuam um sistema já falido, estabelecendo uma falsa sensação de normalidade (Ferreira, 2004).

O desenvolvimento da sociedade atual gerou uma fase em que os riscos sociais, políticos, econômicos, individuais tendem cada vez mais a colocar-se fora do alcance das instituiçıes estabelecidas para a sua supervisão e controle (García, 2004; Zanirato et al., 2008).

Apesar disso, não se exclui a importância da legislação como instrumento para condicionar o acesso ao recurso, o consumo e a repartição dos benefícios e custos. A restrição a perfuraçıes de novos poços na área é o principal ponto positivo das normas editadas, especialmente porque ocorreu graças aos esforços conjugados do Comitê de Bacia $^{5}$ do rio Pardo.

\footnotetext{
5 O Os comitês de bacias Hidrográficas são colegiados instituídos por Lei, no âmbito do Sistema Nacional de Recursos Hídricos e dos Sistemas Estaduais. Esses entes são considerados a base da gestão participativa e integrada da água, têm papel deliberativo e são compostos por representantes do Poder Público, da sociedade civil e de usuários de água e podem ser instalados em águas de domínio da União e dos Estados. Em livro organiza-
}

A edição dessa deliberação fortaleceu o papel do comitê na gestão das águas. Mas ele não tem competência para agregar setores que, embora não sejam diretamente vinculados com a questão hídrica, têm impacto direto no binômio quantidade e qualidade.

Por isso é fundamental o papel da administração local em estabelecer normas e políticas que disciplinem o uso e ocupação do solo, principalmente nas áreas de recarga. A proteção do aqüífero Guarani não se efetivará pela evolução espontânea da sociedade e do mercado, mas sim por meio de um comportamento ativo do Poder Municipal que vise promover o adequado manejo desse recurso (Arenas, 2003).

Não basta a edição desenfreada de leis para resolver a situação das águas subterrâneas em Ribeirão Preto ou mesmo no âmbito Estadual e Federal, visando apenas dar uma falsa sensação de segurança, dissimulando as origens e conseqüências sociais dos perigos. É imprescindível a implementação de políticas públicas para a sustentabilidade desse aqüífero, isto é, a orientação das açıes públicas (planos, programas e projetos) motivada pelo reconhecimento da limitação ambiental fundamental dos recursos, sem os quais nenhuma atividade humana é possível, o que implicaria impedir uma exploração ruinosa do Aqüífero Guarani e manter a sua capacidade de regeneração e absorção (Cavalcanti,1999). Para atingir tal fim, as açıes devem ser integradas e articuladas com outras políticas de desenvolvimento, referentes, por exemplos, à economia, ao social, aos transportes, à habitação, ao saneamento básico, à saúde pública, à agricultura, etc.

Em paralelo a esse movimento, cabe lembrar a necessidade de alteração do estilo

\footnotetext{
do por Ribeiro (2009a), vários autores discutem os impasses do funcionamento dos comitês de bacia, como Valencio (2009), que critica a ausência de setores marginais nos comitês, Jacobi (2009), que analisa a capacidade de estabelecer pactos nessa instituição e Ribeiro (2009b), que aborda as dificuldades em se construir consensos ao reunir atores com interesses tão diversos.
} 
de vida baseado no consumo de bens. Como alertou Ribeiro (2008b), o uso da água aumentou quatro vezes mais que a população mundial nas últimas décadas. Portanto, se no passado foi possível viver com menos água, nada impede que essa situação volte a ocorrer.

\section{Considerações finais}

As áreas de recarga diante de sua vulnerabilidade natural constituem as zonas de maior vulnerabilidade frente à sociedade de risco e a todas externalidades indesejadas. Essa superfície, mapeada por diversos estudos geológicos, é permeada por ameaças e disputas de poder.

A proteção e conservação do Aqüífero Guarani no município não será uma tarefa fácil. Ela pressupıe conciliar uma série de interesses opostos, que no caso das águas subterrâneas incluiu a concorrência dos diferentes usuários da água e dos diversos usos e ocupaçıes do solo, sem esquecer a vulnerabilidade do aqüífero. Dito isso, a proteção do aqüífero, sem uma diretriz nacional que a norteie aliado a um contexto marcado por pressies econômicas e políticas, será uma tarefa complexa não apenas em Ribeirão Preto, mas como em toda a zona de recarga.

O risco é indissociável da política. A forma como se dá a organização do território, a distribuição dos bens e o uso dos recursos naturais pressupıe uma aposta do poder público sobre o futuro. O caso de Ribeirão Preto é particularmente preocupante, uma vez que apesar de ter vivenciado momentos favoráveis à criação de uma política de gestão em virtude da repercussão do assunto graças à edição do Projeto Aqüífero Guarani e da conseqüente inserção do tema na mídia, o que gerou o interesse da sociedade e dos políticos, as açıes foram muito tímidas. Dito isso, indagase como irá se operar a gestão nos demais municípios da zona de recarga do Guarani, onde a dependência sobre o recurso, o conhecimento da sociedade e a disponibilidade de dados é menor.

O risco motiva as escolhas políticas pelo viés da regulamentação. A falta de uma política adequada para esse aqüífero indica que ele não é prioridade e que a água do município é preterida por setores econômicos como a construção civil e a agricultura. O poder público aposta nos prognósticos mais positivos e acredita que o abastecimento não está ameaçado. Afinal, a contaminação é restrita ao ponto do lixão, os estudos com agroquímicos ainda são poucos e a quantidade de substâncias nocivas nunca ultrapassou os limites estabelecidos e, no tocante a expansão urbana, julgou-se que a densidade de 850 hab/ha é adequada para manter a recarga.

As medidas para gestão do aqüífero se limitam à edição de leis com o objetivo de dar uma satisfação social a alguns setores da sociedade melhor organizados e aos organismos internacionais envolvidos no Projeto Aqüífero Guarani. Porém, não se traduzem em políticas públicas de fato, restringindo-se a meros discursos legislativos.

A falta de uma sociedade organizada, participativa e informada ajuda a manter esse cenário. Além de uma educação ambiental, a sociedade ribeirãopretana precisa de uma educação política, que se contraponha à dinâmica perversa do mercado, onde poucos interiorizam os lucros e muitos convivem com as externalidades negativas e com os riscos.

A ausência de um sistema informacional acessível ao público geral e de fácil entendimento é outra agravante para a gestão desse recurso. Ele poderia contribuir muito para formar uma sociedade consciente, crítica e ativa nos comitês, conselhos e na vida política de maneira geral.

Enquanto não forem reconhecidas as ameaças ao aqüífero Guarani pela sociedade civil, dificilmente ele será privilegiado pelos administradores públicos. $\mathrm{Na}$ sociedade de risco não existem objetos limpos, há incertezas sobre todas as relaçıes e conseqüências inesperadas sempre podem ocorrer. Cabe à sociedade definir a hierarquia dos riscos que está disposta a aceitar. No entanto, tal decisão, apesar da aparência democrática legitimada pela 
participação representativa, tem sido realizada por minorias economicamente mais fortes e organizadas.

\section{Referências bibliográficas}

AGÊNCIA NACIONAL DE ÁGua. Panorama do enquadramento dos corpos d'água do Brasil e panorama da qualidade das águas subterrâneas no Brasil 2007. In: CONEJO, J. G. L; COSTA, M. P. \& ZOBY, J. L. G. (coord.). Caderno de Recursos Hídricos v. 5. Brasília: ANA, 2007.

ARENAS, F. El ordenamiento sustentable del territorio regional Los gobiernos regionales entre la necesidad y la realidad. Revista de Geografia Norte Grande, 2003, $\mathrm{N}^{\circ} 30$, p. 45-54.

BECK, U. La sociedad del riesgo. Hacia una nueva modernidad. Barcelona: Paidós, 1986.

BORGHETTI, N.; BORGHETTI, J. R. \& ROSA, E. F. F. Aqüífero Guarani-A verdadeira integração dos países do Mercosul. Curitiba: Imprensa Oficial, 2004.

CALVO, G. T. F. Algunas cuestiones sobre geografía de los riesgos. Scripta Nova. Revista Electrónica de Geografía y Ciencias Sociales, 1997, No 10. Disponível em Internet: http://www.ub.es/geocrit/sn-10.htm

CALVO GARCÕA-TORNEL, F. Sociedades y territorios en riesgo. Barcelona: Ediciones del Serbal, 2001.

CAMARGO, E. e RIBEIRO, E. A proteção jurídica das águas subterrâneas no Brasil. In: RIBEIRO, W. C. (Org.). Governança da água no Brasil: uma visão interdisciplinar. São Paulo: Annablume/FAPESP/CNPq, 2009.

CARPENTER, R. A. Risk Assessment. In: VANCLAY, F. \& BRONSTEIN, D. A. Environmental and social impact assessment. New York: John Wiley \& Sons, 1995.

CAVAlCANTI, C.. Política de governo para o desenvolvimento sustentável: uma introdução ao tema e a esta obra coletiva. In: CAVALCANTI, C. (org) Meio ambiente, desenvolvimento sustentável e políticas públicas. São Paulo: Recife: Cortez; Fundação Joaquim Nambuco, 1999.

CAUBET, C. G. Os contextos normativos brasileiros em matéria de águas subterrâneas. In: RIBEIRO, W. C. (org.). Governança da água no Brasil: uma visão interdisciplinar. São Paulo: Annablume/ FAPESP/CNPq, 2009.

CAUBET, C. G. O escopo do risco no mundo real e no mundo jurídico. In: VARELLA, M. D. (org.) Governo dos riscos. Brasília: Rede Latino-Americana-Européia sobre Governo dos Riscos, 2005, p. 41-55.

DEMAJOROVIC, J. Sociedade de risco e responsabilidade socioambiental. São Paulo: Senac, 2003.

FERREIRA, H. S. O risco ecológico e o princípio da precaução in estado de direito ambiental: tendências: aspectos constitucionais e diagnósticos. Rio de Janeiro: Forense Universitária, 2004.

GARCIA, E. Medio ambiente y sociedad: la civilización industrial y los límites del planeta. Madrid: Aliança Editoria S. A., 2004.

GIDDENS, A. As conseqüências da modernidade. São Paulo: Ed. Unesp, 1991.

GIDDENS, A. Modernidade e identidade. Rio de Janeiro: Zahar Ed., 2002.

GOMES, M. A. F.; SPADOTTO, C. A. \& LANCHOTTE, V. L. Ocorrência do herbicida Tebutiuron na água subterrânea na microbacia do Córrego Espraiado, Ribeirão Preto-SP. Pesticidas: Revista de Ecotoxicologia e Meio Ambiente, 2001, vol. 11, p. 65-76.

HERMITTE, M. A. Os fundamentos jurídicos da sociedade do risco-Uma análise de U. Beck n Governo dos Riscos. In: VARELLA, M. D. (org.) Governo dos riscos. Brasília: Rede Latino-Americana-Européia, 2005, p. 11-40.

INSTITUTO BRASILEIRO DE GEOGRAFIA E ESTATÍSTICA (IBGE). IBGE 
Cidades. Bco de dados, 2006. Disponível em Internet: http://www.ibge.com.br/ cidadesat/default.php

JACOBI, P. Governança da água no Brasil. In: RIBEIRO, W. C. (org.). Governança da água no Brasil: uma visão interdisciplinar. São Paulo: Annablume/ FAPESP/CNPq, 2009.

LATOUR, B. Políticas da natureza: como fazer ciência na democracia. Bauru: Edusc, 2004.

LEMKOW, L. Sociología ambiental: pensamiento socioambiental y ecología social del riesgo. Barcelona: Icaria, 2002

MONTEIRO, R. C. Estimativa spaço temporal da superfície potenciométrica do sistema aqüífero Guarani na cidade de Ribeirão Preto (SP). En: Rio Claro, Dissertação (Mestrado em Geociências e Meio Ambiente), Instituto de Geociências e Ciências Exatas, Universidade Estadual Paulista, 2003.

NOVEMBER, V. Les territoires du risque: le risque comme objet de refléxion géographique. Berna: Lang, 2002.

PESSOA, M C. P. Y.; GOMES, M A. F.; NEVES, M. C. et al. Identificação de areas de exposição ao risco de contaminação de águas subterrâneas pelos herbicidas Atrazina, Diuron E Tebutiuron. Pesticidas: Ecotoxicologia e Meio Ambiente, +2003 , vol. 13, p.111-122.

PERTICARRARI, C. Plano de bacia do Rio Pardo. In: DAEE/IG. (org.). Memória seminário aqüífero Guarani. Anais. Ribeirão Preto: DAEE, 2003, p. 90-95.

PORTO, M. F. Riscos, incertezas e vulnerabilidade: transgênicos e os desafios para a ciência e a governança. Revista de Sociologia Política: Política e Sociedade, 2005, vol. 4, No 7, p. 77-104.

RIBEIRO, W. C. (org.). Governança da água no Brasil: uma visão interdisciplinar. São Paulo: Annablume/FAPESP/CNPq, 2009a.

RIBEIRO, W. C. Impasses da governança da água no Brasil. In: RIBEIRO, W. C. (org.).
Governança da água no Brasil: uma visão interdisciplinar. São Paulo: Annablume/ FAPESP/CNPq, 2009b.

RIBEIRO, W. C. Aqüífero Guarani: gestão compartilhada e soberania. Estudos avançados, 2008a, vol. 22, No 64, p. 227238. Disponível em Internet: http:// www.scielo.br/scielo.php?script=sci_arttext \&pid=S010340142008000300014\&lng=pt\&nrm=iso.

RIBEIRO, W. C. Geografia política da água. São Paulo: Annablume, 2008b.

SÃO PAuLO. COMPANHIA DE TECNOLOGIA DE SANEAMENTO AMBIENTAL. Relatório da relação de áreas contaminadas do Estado de São Paulo. São Paulo: Companhia de tecnologia de saneamento ambiental, 2007. Disponível em: http://www.cetesb.sp.gov.br/Solo/ relatorios.asp

SETZER, J. Panorama do principio da precaução: o direito do ambiente face aos novos riscos e incertezas. Dissertação de Mestrado. São Paulo: Programa de Pósgraduação em Ciência Ambiental (Procam), Universidade de São Paulo, Brasil, 2007.

SINELLI, O. (coord.). Mapa geológico do nordeste do Estado de São Paulo. Escala 1:50.000 - Folhas Serrana, Ribeirão Preto, Cravinhos e Bonfim Paulista. Ribeirão Preto: Convênio CNEC/FFCL USP, 1973. (Documento Digitalizado pelo Instituto Geológico).

VALENCIO, N. F. Governança das águas: a participação social como quimera. In: RIBEIRO, W. C. (org.). Governança da água no Brasil: uma visão interdisciplinar. São Paulo: Annablume/FAPESP/CNPq, 2009.

VARELLA, M. D. A dinâmica da percepção pública de riscos e as respostas do direito internacional econômico. In: VARELlA, M. D. Governo dos Riscos. Brasília: Rede Latino Americana-Européia, 2005, p. 136-157.

VEYVRET, Y. Os riscos: o homem como agressor e vitima do meio ambiente. São Paulo: Contexto, 2007. 
VIDAL DE LA BLACHE, P. A Geografia Política a propósito dos escritos de Friedrich Ratzel. In: HAESBAERT, R. e SOUCHAUD, S. (trad.) Annales de Géographie $N^{\circ} 32$, año 7, 15 de março de 1898. Disponível em Internet: www.uff.br/geographia/rev_07/ lablache7.pdf.

VILLAR, P. C. Gestão das áreas de recarga do aqüífero Guarani: o caso de Ribeirão Preto. Dissertação de Mestrado. São Paulo: Programa de Pós-graduação em
Ciência Ambiental (Procam), Universidade de São Paulo, Brasil, 2008.

ZANIRATO, S. H.; RAMIRES, J. Z. S.; AMICCI, A. G. N.; ZULIMAR, M. R. \& RIBEIRO, W. C. Sentidos do risco: interpretaçıes teóricas. Biblio $3 W$, Revista Bibliográfica de Geografía y Ciencias Sociales, 2008, vol. XIII, No 785. Disponível em Internet: http://www.ub.es/geocrit/b3w785.htm 